\title{
Contribuições ao estudo de cidades médias: Araguaína, Gurupi e Palmas, no Tocantins
}

\section{Contributions to the study of middle cities: Araguaína, Gurupi and Palmas in the Tocantins}

Reges Sodré - Mestrando em Geografia na Universidade Federal de Uberlândia. Bolsista da Coordenação de Aperfeiçoamento de Pessoal de Nível Superior (CAPES). E-mail: regessodre@gmail.com

Julio Cesar de Lima Ramires - Doutorado em Geografia Humana pela Universidade de São Paulo e estágio de pós-doutorado na Universidade Federal Fluminense. Atualmente é professor do Instituto de Geografia da Universidade Federal de Uberlândia. E-mail: ramires_julio@yahoo.com.br

\section{Resumo}

Tem por objetivo analisar a importância das cidades médias de Araguaína, Gurupi e Palmas no Tocantins, tendo como recorte analítico os processos de concentração econômica e espacial nelas verificados vis-à-vis as demais cidades do estado. Para tanto, na primeira seção levantamos argumentos em favor dos processos de desconcentração econômica e espacial do território brasileiro a partir de 1970. Em seguida, tratamos da formação e crescimento das cidades médias do Tocantins, para, finalmente, entrarmos no objetivo central deste trabalho, ou seja, os papéis das cidades médias tocantinenses. Pudemos constatar que, com a ausência de metrópoles no Tocantins, são as cidades médias que assumem o protagonismo socioeconômico, atraindo os principais investimentos e comandando a rede urbana, de um lado, polarizando um conjunto amplo de centros locais e pequenas cidades, pela oferta de bens e serviços especializados e diversificados, de outro, estabelecendo amplas interações espaciais com o espaço nacional e internacional.

\section{Palavras-chave}

Concentração Econômica e Espacial. Cidades Médias. Tocantins.

\begin{abstract}
This study has the purpose to analyze the importance of medium-sized cities of Araguaína, Guripi, Palmas in Tocantins, with the analytical approach the processes of economic and spatial concentration checked them vis-à-vis the other cities of the state. To this end, the first section raised arguments in favor of economic and spatial deconcentration processes of Brazil from 1970. Then treat the formation and growth of medium-sized cities of Tocantins, to finally enter the central objective of this work, that is, the roles of the medium-sized cities tocantinenses. We could verify that with the absence of metropolis in Tocantins, the medium-sized cities assume the socio-economic protagonism, attracting the main investment and commanding the urban network on the one hand, polarizing a large set local centers and small cities, for the supply of goods and services specialized and diversified, on the other, establishing broad spatial interactions with the national and international space.
\end{abstract}

\section{Keywords}

Economic and Spatial Concentration. MediumSized Cities; Tocantins. 


\section{INTRODUÇÃO}

Em alguns segmentos da rede urbana da Amazônia Legal, como no estado do Tocantins, o avanço contundente do capital nacional e multinacional se dá principalmente a partir dos anos de 1990. Os principais locais de sua materialização são as regiões agrícolas, as áreas de recursos naturais escassos e as cidades médias. Neste trabalho, priorizamos as recentes dinâmicas encontradas nas cidades médias do referido estado, tendo em vista as relações da cidaderegião, a interiorização do capital nacional/multinacional e o encontro dessas dinâmicas com os agentes empresariais locais que, em síntese, engendram os processos de concentração econômica e espacial.

Do ponto de vista teórico-metodológico, apoiamo-nos em Sposito (2004), Andrade e Serra (1998), Diniz e Crocco (1996), Santos e Silveira (2009), Santos (2012), Harvey (1998) e Bauman (2008), a respeito das discussões sobre a (des) concentração econômica e espacial ocorridas no âmbito do território vernáculo, influenciado pela reestruturação do capitalismo internacional e as ações estatais de desenvolvimento e crescimento do Brasil.

O crescimento e formação das cidades médias de Araguaína, Gurupi e Palmas é discutido a partir das pesquisas sobre rede urbana e de dados econômicos e populacionais apresentados pelo IBGE e de algumas publicações sobre a região em estudo. Por fim, a concentração econômica e espacial nas cidades médias é trabalhada pelo viés quantitativo, em que se mensura a quantidade de estabelecimentos do comércio e serviços, indústria, emprego formal, índice de consumo, acesso à internet e uso de computadores presentes nas cidades médias em relação às outras cidades por meio de dados da Revista Exame, Instituto Brasileiro de Executivos de Varejo e Mercado de Consumo (IBEVAR), IPC Marketing Editora, Ministério de Trabalho e Emprego (MTE), IPEADATA, Instituto Brasileiro de Geografia e Estatística (IBGE), e pela Fundação Getúlio Vargas (FGV) e Centro de Políticas Sociais (CPS). Procurou-se identificar onde os capitais mais especializados/diversificados, de atuação nacional/internacional, estão presentes no estado do Tocantins, cujo resultado expressa a pujança das cidades médias.

\section{DESCONCENTRAÇÃO,RECONCENTRAÇÃOECENTRALIZAÇÃO ECONÔMICA E ESPACIAL NO BRASIL NO FINAL DO SÉCULO XX}

Segundo Sposito (2004, p. 222-223), “a concentração espacial está associada à localização dos capitais, entendidos como infraestruturas", ao passo 
que "a centralização espacial refere-se ao capital produtivo centralizado e não apenas ao capital fixo". Em outras palavras, a concentração espacial pode-se, e aqui tomaremos essa perspectiva, associar a uma dimensão quantitativa na medida em que é mensurada pela quantidade de empresas presentes em um espaço (filiais, e formas de associações de capital), enquanto a centralização espacial está ligada aos comandos exercidos pelas empresas ante a sua localização espacial (matrizes). Apesar de se distinguirem, concentração e centralização se integram e se complementam em alguns casos.

Nos trabalhos de Andrade e Serra (1998), Sposito e Sposito (2012) Sposito (2004; 2009), Diniz e Crocco (1996), Santos e Silveira (2009) encontramos duas linhas complementares que delineiam o processo de desconcentração industrial, incluindo também os serviços e o comércio no território brasileiro. A primeira se refere à reestruturação econômica do sistema capitalista e a segunda aos papéis desempenhados pelo Estado brasileiro perante os interesses de desenvolvimento social e crescimento econômico.

A partir dos anos 1970 e 1980, o sistema capitalista sofreu reestruturação em seus mecanismos de acumulação, marcado pela passagem do sistema fordista de produção ao de acumulação flexível, como resultado das crises de superacumulação (HARVEY, 1998). A respeito da nova estrutura de acumulação capitalista, Harvey (1998, p. 140) pontua suas características:

A acumulação flexível, como vou chamá-la, é marcada por um confronto direto com a rigidez do fordismo. Ela se apoia na flexibilidade dos processos de trabalho, dos mercados de trabalho, dos produtos e padrões de consumo. Caracteriza-se pelo surgimento de setores de produção totalmente novos, novas maneiras de fornecimentos de serviços financeiros, novos mercados e, sobretudo, taxas altamente intensificadas de inovação comercial, tecnológica e organizacional. A acumulação flexível envolve rápidas mudanças dos padrões geográficos, criando, por exemplo, um vasto movimento no emprego no chamado 'setor de serviços', bem como conjuntos industriais completamente novos em regiões até então subdesenvolvidas [...]. Ela também envolve um novo movimento que chamarei de 'compressão do espaço-tempo' no mundo capitalista - os horizontes temporais da tomada de decisão privada e pública se estreitaram, enquanto a comunicação via satélite e a queda dos custos de transporte possibilitaram cada vez mais a difusão imediata dessas decisões num espaço cada vez mais amplo e variado.

Essas mudanças ocorreram apoiadas no meio técnico-científicoinformacional, "base material da globalização" (SANTOS, 2012, p. 192), o qual tem permitido a diminuição das distâncias - para um número reduzido de agentes -, pelo melhoramento dos sistemas de transporte e comunicação, constituindo- 
se a conectividade, uma de suas características mais avançadas. O referido autor destaca ainda a ampliação dos contextos e aceleração contemporânea como características do atual período histórico.

Bauman (2008) apresenta uma interessante perspectiva de mudança relacionada ao capitalismo mundial a partir da segunda metade do século XX. $\mathrm{O}$ autor propõe o surgimento do consumismo, da sociedade de consumidores e da cultura consumista. Perfazendo essas três ideias, está posto que: a) é central na vida das pessoas, atualmente, consumir cada vez mais, dado a prerrogativa do constante descartar aquilo que consumimos; b) a ampliação dos mercados de bens e serviços destinados a atender a todas as classes sociais, ainda que resguardadas os padrões de qualidade/quantidade a que elas podem pagar; c) e, finalmente, o consumo como padrão e termômetro das relações sociais.

Sposito e Santos (2012) acrescentam o crescimento acentuado das multinacionais de países periféricos ocorrido no final do século XX como mais uma dinâmica relacionada às reestruturações do sistema capitalista. Esse processo é verificado no acréscimo dos Investimentos Externos Diretos (IED) no sentido sul-sul e sul-norte e não somente o tradicional movimento vetorial norte-sul.

Sposito e Sposito (2012, p. 3) destacam que a "prevalência das transformações sobre as permanências marca nosso tempo", justificando, assim, "o reconhecimento de ruptura em relação a dinâmicas anteriores e, portanto, de adoção do conceito de reestruturação, já que se alteraram as bases sobre as quais se assentam" a acumulação capitalista.

No Brasil o Estado assumiu a missão de integração e desenvolvimento nacional, cujo desenho torna-se visível no pós Segunda Guerra Mundial (SANTOS; SILVEIRA, 2008). Várias ações foram elaboradas, tais como os Planos Nacionais de Desenvolvimento (PND) e Planos de Integração Nacional (PIN), visando, entre outras coisas, fomentar o desenvolvimento do território brasileiro, interferindo em seus sistemas de engenharia e nas estruturas urbanas e regionais. Além do claro sentido de interiorização da urbanização, tangível, por exemplo, no Programa Nacional de Apoio às Capitais e Cidades de Porte Médio, contido no II PND.

Dessa forma:

Nos últimos decênios, o território conhece grandes mudanças em função de acréscimos técnicos que renovam a sua materialidade, como resultado e condição, ao mesmo tempo, dos processos econômicos e sociais em curso. Destacamos, aqui, as infraestruturas de irrigação e as barragens, os portos e aeroportos, as ferrovias, rodovias e hidrovias, as instalações ligadas à energia elétrica, refinarias e dutos, as bases materiais das telecomunicações, além de semoventes e insumos ao solo (SANTOS; SILVEIRA, 2008, p. 55). 
O corolário para a rede urbana vernácula dessas dinâmicas, reestruturação do capital mundial e ações de modernização do território brasileiro, incluindo sua maior integração a economia mundial, foi relativa, isto é, dentro de certos limites. Há, nesse sentido, interiorização do capital através da desconcentração da produção e difusão do consumo, mas com forte centralização dos comandos, notadamente em cidades do centro-sul brasileiro (SPOSITO, 2004; AMORIM FILHO; SERRA, 2001).

Para se ter uma ideia da centralização espacial no território brasileiro, em 2013, segundo a Revista Exame, dos 200 maiores grupos econômicos do país, 105 adotou o estado de São Paulo como sede, sendo seguido pelo Rio de Janeiro, que aparece com 28 grupos econômicos. Desse modo, a região Sudeste fica com $76,5 \%$ das sedes dos maiores grupos com atuação nacional e o Sul, o Nordeste e o Centro-Oeste, com 16\%, 5\%, 2,5\%, respectivamente. A região Norte não aparece com nenhum estado nesse ranking.

É importante reconhecer, nesse ínterim, a força que ganham as articulações de escalas geográficas, quando diversos agentes põem em relação múltiplos pontos e redes, que funcionam como estruturas articuladas ao avanço do processo de acumulação. Ainda que não seja o ponto fulcral de nossa discussão, a desconcentração econômica e espacial é indissociável e condicionada às mudanças de atuação escalares dos agentes e das cidades, ao passo que a reforça, possibilitando, assim, desconcentração centralizada de capital.

A desconcentração ocorre principalmente nos setores de comércio e serviços que "restringiu-se, num primeiro momento, às metrópoles e grandes cidades". Porém, "recentemente, com a ampliação do consumo, incluso entre os segmentos de menor poder aquisitivo, os grandes capitais comerciais e de serviços passaram a fazer escolhas locacionais que incluem os extratos imediatamente inferiores da hierarquia urbana" (SPOSITO, 2009, p. 58).

Ainda segundo Sposito (2009, p. 57-58), essa assertiva se deve ao fato de que "ao contrário da atividade de produção industrial, em que a centralização de capitais pode ou não gerar concentração territorial da produção, no caso do setor comercial e de serviços, centralização de capitais nas mãos" de um reduzido "número de grupos econômicos, precisa da ampliação da base territorial do consumo, ou seja, maior número de pontos de vendas".

Esse processo nos interessa, primordialmente, porque os papéis das cidades médias ${ }^{1}$ do Tocantins ganham relevância na dimensão comercial e de serviços.

\footnotetext{
Entende-se, neste escrito, por cidade média, "aquelas cidades que assumem um determinado papel na estrutura urbana regional como centro sub-regional, não sendo simplesmente centros locais", nem metrópoles, "mas núcleos urbanos com capacidade de polarizar e influenciar um número significativo de núcleos menores e articular relações de toda ordem" (TRINDADE JR., 2011, p. 137).
} 
Retomando Bauman (2008), podemos entender que os imperativos da sociedade de consumidores, junto às outras condições técnicas-científicas-informacionais que lhe dão base infraestrutural, atingem diretamente o espaço e, especialmente, a rede urbana por meio da difusão do consumo e de hábitos urbanos, como alimentação fora de casa, que outrora eram restritos aos centros metropolitanos. Nesse sentido, de acordo com Andrade e Serra (1998, p. 2), "as cidades médias parecem deter papel de destaque na distribuição espacial da riqueza nacional".

Para Santos (2009, p. 54), a dinâmica da expansão do consumo "leva à ampliação do fenômeno da urbanização", enquanto as cidades mudam de conteúdo e deixam de ser dos notáveis para se transformarem em cidades econômicas.

Segundo Santos (2009, p. 100), "o movimento de concentração-dispersão, próprio da dinâmica territorial em todos os tempos, ganha, todavia, expressões particulares segundo os períodos históricos". No Brasil, "ao longo de sua história territorial, as tendências concentradoras atingiam número maior de variáveis, presentes somente em poucos pontos do espaço" (SANTOS, 2009, p. 100). No entanto, segundo o autor, "as tendências à dispersão começam a se impor e atingem parcelas cada vez mais importantes dos fatores, distribuídos em áreas mais vastas e lugares mais numerosos" (SANTOS, 2009).

Vê-se, portanto, que a rede urbana brasileira torna-se mais complexa, a despeito da complexidade funcional de seus centros, das interações espaciais entre eles, das diferenciações e das relações de competição/complementaridades (CORRÊA, 2001). Diante disso, bens e serviços especializados podem ser encontrados em centros de escalão inferior da rede urbana, fruto de sua especialização e diversificação em vários segmentos de mercado. Ocorre, porém, que não necessariamente tal centro exerça a efetiva gestão do território, embora estabeleçam relações globais, deixando de ser tal atributo uma exclusividade das metrópoles. Pode-se destacar ainda que, pela intensificação dos usos do território, modificações ocorrem no padrão espacial da rede urbana, tornando-o uma realidade complexa e relativamente efêmera, especialmente na Amazônia Legal.

\section{O CONTEXTO DA FORMAÇÃO E DO CRESCIMENTO DAS CIDADES MÉDIAS DO TOCANTINS}

A urbanização no estado do Tocantins é ainda recente e com a ausência do fenômeno metropolitano. Delimitamos aqui dois períodos principais que marcam as recentes dinâmicas da rede urbana regional e que explicam diretamente a formação das cidades médias e as lógicas econômicas que sobre elas se instalam, 
como a concentração espacial e econômica. O primeiro período foi de 1960 até a criação do Tocantins, quando, então, se iniciou o segundo período.

O trabalho de Brito (2009) mostra que a rede urbana do Tocantins, antes da construção da rodovia Belém-Brasília nos anos de 1960, estava bastante fragmentada e desarticulada, com pouca complexidade dos centros urbanos e incipientes interações espaciais entre eles. Os principais centros eram aqueles localizados em torno dos rios Araguaia e Tocantins, tendo em vista a ausência de rodovias, além de haver precárias condições das estradas (não pavimentadas) e o irrisório transporte aéreo. Dessa forma, a construção da Belém-Brasília no norte goiano provocou, de imediato, a proliferação de vários núcleos urbanos em suas margens e a estagnação daquelas que se localizavam no entorno dos mencionados rios.

Antes de 1950 existiam oficialmente apenas 13 municípios no Tocantins e, portanto, a mesma quantidade de cidades (de acordo com os critérios oficiais de classificação de cidades pelo IBGE). Na década de 1950 foram criados 18 municípios e até 1989 mais 47, significando, assim, que a partir de 1950 foram criados 90,62\% dos municípios do Tocantins (IBGE, 2012).

Essas realidades surgiram no contexto de expansão da fronteira agrícola nacional, com intensos investimentos do governo federal realizados, principalmente, no âmbito do Plano de Integração Nacional, que tinha por objetivo: a) reduzir a tensão em áreas rurais e urbanas, no Nordeste do país, estimulando a imigração para áreas previamente selecionadas na Amazônia; b) considerações de ordem geopolítica, como a "nacionalização dos espaços vazios"; c) a elevação da produção de alimentos para os mercados internos e externos; d) a criação de novos espaços para o investimento privado, no sentido de intensificar o ritmo de acumulação interna de capital (MACHADO, 1992).

Assim, "a estruturação da fronteira se viabiliza pela mediação do urbano que é a base logística para o projeto de sua rápida ocupação” (BECKER, 1985, p. 360). Entre os movimentos de ocupação que podem ser identificados está "a expansão-consolidação de centros regionais, sub-regionais e locais que constituem a base de operações produtivas de frentes impulsionadas por iniciativa do Estado" ao longo da rodovia Belém-Brasília, os quais "recebem investimentos estatais estratégicos" (BECKER, 1985, p. 360).

Inseriram-se nessa conjuntura duas cidades do norte goiano, Araguaína e Gurupi, localizadas em posição privilegiada, sendo a primeira no norte e a segunda no sul, ambas às margens da rodovia Belém-Brasília. Elas, então, começaram a ganhar destaque na rede urbana regional pelas funções ante a produção agrícola, comércio, serviços e circulação da força de trabalho. 
Os dados apresentados nas pesquisas sobre rede urbana publicados pelo IBGE em 1972, 1987 e 1993 demonstram os crescentes papéis desempenhados por essas cidades na rede urbana do norte goiano, traduzidos pelo aumento da centralidade e das interações espaciais entre elas e com centros externos à rede. Da mesma forma, fica evidente quão fragmentada era a rede urbana, nos levando a afirmar que de fato existiam "pequenos seguimentos de rede" e não propriamente uma rede regional como vai se configurar no final do século XX e início do XXI.

Conforme o IBGE (1972; 1970), em 1970, Araguaína, com população de 37.780 habitantes, exercia a função de Centro Local A no quarto nível hierárquico, influenciando 5 centros (Ananás, Arapoema, Colinas de Goiás, Itaporã de Goiás e Xambioá), cuja população chegava em torno 34.477 mil pessoas. De acordo com o IBGE (1972, p. 16), a atuação deste tipo de centro "se faz na prestação de serviços procurados a curta distância: serviço bancário, ginásio, varejo comum, médico de clínica geral".

Em 1980 (IBGE, 1987; 1980) Araguaína, com 72.138 pessoas, ascendeu à categoria de principal cidade do norte goiano, exercendo o papel de Centro Sub-Regional, subordinando 11 centros, cuja população chegava a 153.001 mil pessoas. Isso significou o desempenho de mais funções entre essa cidade e aquelas localizadas na região de influência. Apesar disso, a rede urbana continuava com pouca integração territorial e de mercado, sendo a infraestrutura de ligação entre as cidades, em sua forma material e informacional, um gargalo a ser superado.

Enquanto isso, Gurupi, em 1970, tinha 24.660 habitantes (IBGE, 1972; 1970) e desempenhava a função de Centro Local B também no quarto nível hierárquico, embora exercesse influência sobre um menor número de municípios (eram quatro municípios subordinados a Gurupi, os quais tinham população de 18.129 habitantes) e estabelecesse menores interações espaciais.

A cidade de Gurupi em 1980 (IBGE, 1987; 1980) possuía 38.686 habitantes e era um Centro de Zona com seis municípios em sua área de influência, cuja população chegava a 68.521 habitantes. Essa cidade desempenhava as funções básicas no âmbito da hierarquia urbana e estava em "competição" com Porto Nacional, que já possuíra ligação com a rodovia Belém-Brasília por meio da construção de ponte sobre o rio Tocantins.

A partir da criação do Tocantins (1988) e, também, da capital Palmas (1990) - que exercia funções ligadas, incialmente, apenas ao sistema administrativo - temse a formação mais nítida de uma rede urbana ensejado pelo maior número de centros, pelas relações estabelecidas entre eles e o aprofundamento das funções desempenhadas, delineadas pela intensificação da atuação do capital nacional e internacional. 
Araguaína, com 103.315 habitantes, amplia sua região de influência a 40 centros, extrapolando os próprios limites do Estado do Tocantins (IBGE, 2000). A ascensão dessa cidade na rede hierárquica foi, simultaneamente, condição para e reflexo da divisão territorial do trabalho imposta pelo capital nacional ao Tocantins e, a partir de 1990, também da maior presença do capital internacional.

Segundo Ajara et al. (1991, p. 40), nessa época "quase todas as atividades comerciais, administrativas e financeiras e os serviços sociais existentes na área" estavam em Araguaína. Assim, a referida cidade exercia "um forte processo de polarização sobre sua área de influência, em função de sua expressão econômica e demográfica, vis-à-vis a situação de miséria das demais vilas e cidades” (p. 40).

Por outro lado, Gurupi aproveitou-se das condições propiciadas pela criação do Tocantins e de vários municípios, passou a ter centralidade forte para uma cidade média, ampliando sua área de influência para 38 centros (IBGE, 2008). Essa condição foi, no entanto, efêmera, pois quando da estruturação da capital Palmas, nas duas décadas seguintes, esta passou a ter o comando da rede urbana regional, diminuindo os papéis e a centralidade exercida por Gurupi e Porto Nacional (IBGE, 2008).

Guardada essa contingência da cidade de Gurupi, esta e Araguaína, no final do século XX, poderiam ser classificadas como cidades médias, tendo em vista as funções exercidas em âmbito regional. Tal condição foi erigida não somente pelas funções desempenhadas por tais centros, mas também pela tenaz estrutura social e econômica dos centros locais e cidades pequenas ${ }^{2}$ em seus entornos, o que fortaleceu seus papéis na rede urbana ${ }^{3}$.

O crescimento dessas cidades esteve ligado, e ainda está, ao âmbito agrícola, com nítida imbricação das relações cidade-campo e urbano-rural. No caso de Araguaína, a pecuária teve importante papel na ocupação do município e no estímulo à prestação de serviços ao campo, bem como ao processamento de carne bovina advinda de seu município, de sua microrregião geográfica (maior produtora de bovinos do estado) e região de influência na rede urbana. Em Gurupi, além da pecuária, a agricultura modernizada de grãos propiciou o alargamento de serviços a esse segmento destinado. As funções urbanas destinadas a atender as demandas do campo vêm se consolidado atualmente nessas cidades, como apontam Sodré (2014) e Fornaro (2012).

\footnotetext{
A respeito da diferença entre centro local e cidade pequena, ver Fresca (2010).

Ainda que não seja o objeto deste trabalho, é importante destacar que os indicadores sociais sempre foram ruins nas cidades do Norte Goiano, incluindo Araguaína e Gurupi. Entre os indicadores citados por Ajara et al. (1991) estavam alto índice de analfabetismo, mortalidade infantil, baixa parcela da população servida de água tratada e energia elétrica.
} 
A respeito da criação e consolidação de Palmas na rede urbana, Brito (2009, p. 18) afirma que "a cidade apresentou duas etapas no processo de consolidação de seu papel como centro regional, a primeira compreendida nos dez primeiros anos, denominada como 'cidade canteiro de obra', e a segunda, de "cidade consolidada". Na primeira fase, "Palmas foi apresentada como um local estratégico e das oportunidades, processo bastante refletido na mídia, na cidade consolidada, a rede de articulação de transporte permite uma dinâmica comercial e financeira para a cidade" (p. 18) e uma centralidade do transporte aéreo, cujo resultado é a dependência de outras cidades do Tocantins e estados vizinhos.

Bessa e Corado (2011, p. 42) ressaltam que Palmas "passou a atrair a maioria das funções urbanas e também a maior parte da população, inclusive, a população urbana e mão-de-obra migrante". Acrescentam ainda que essa cidade vem se tornando o ponto nodal do estado, em termos de circulação e atração de investimentos locais e nacionais, conferindo à mesma o protagonismo no comando da vida urbana regional.

Assim, conforme os dados da pesquisa Região de Influência das Cidades -2007, realizado pelo IBGE (2008), a capital Palmas exerce a função de Capital Regional B, com centralidade muito forte, Araguaína como Capital Regional C, com nível de centralidade forte, e Gurupi como Centro Sub-Regional B, com centralidade de nível médio.

As cidades médias ganharam, portanto, proeminência na urbanização do estado, pois são os principais centros de consumo e de gestão do território. Nelas estão presentes em maior quantidade e qualidade serviços de transporte, financeiros, comunicação, saúde, educação, administração, jurídicos, empresas do comércio e da indústria, tornando-as áreas de confluência de processos migratórios e da geração de empregos formais.

\section{CONCENTRAÇÃO ESPACIAL E ECONÔMICA NAS CIDADES MÉDIAS DO TOCANTINS}

Para analisarmos a concentração industrial nas cidades médias, frisamos que tal setor no Tocantins é parcimonioso e recente. A produção restringese, majoritariamente, às indústrias de transformação, localizadas em distritos agroindustriais, sendo que 51,08\% delas foram criadas a partir de 1990. De 1970 a 1990 as cidades médias, Gurupi e Araguaína, tinham participação quantitativa no conjunto estadual irrisória, com média de 23\%. A partir da criação de Palmas, somado ao crescimento verificado em Gurupi e Araguaína, a participação dessas 
cidades médias no conjunto estadual subiu para 44,07\%, em 2006, e 48,91\%, em 2012 (IBGE, 2006; 2012; IPEADATA, 1970-1995).

Os dados da Tabela 1, que compreendem um período de 42 anos, indicam o crescimento do comércio e dos serviços nas três cidades médias aqui consideradas, mostrando uma evolução significativa do número de estabelecimentos. A cidade de Araguaína apresenta um crescimento expressivo com taxa média anual de $4,20 \%$, tendo maior incremento absoluto de estabelecimento a partir de 1995, com média de 96 estabelecimentos incrementados anualmente. Gurupi teve taxa média de crescimento de 3,99\%, isto é, praticamente o mesmo crescimento de Araguaína.

Tabela 1: Estabelecimentos comerciais e de serviços nas cidades médias do Tocantins

\begin{tabular}{l|r|r|r|r|r|r}
\hline \multirow{2}{*}{ Cidades } & \multicolumn{7}{|c}{ Comércio e serviços } \\
\cline { 2 - 7 } & 1970 & 1980 & 1985 & 1995 & 2006 & 2012 \\
\hline Araguaína & 401 & 611 & 896 & 1492 & 2256 & 3130 \\
\hline Gurupi & 396 & 451 & 558 & 1449 & 1695 & 2050 \\
\hline Palmas & $\mathrm{x}$ & $\mathrm{x}$ & $\mathrm{x}$ & $\mathrm{x}$ & 3782 & 6220 \\
\hline Demais cidades & 2646 & 2982 & 5859 & 7481 & 9713 & 11416 \\
\hline
\end{tabular}

Fonte: IBGE, 2006; 2012. IPEADATA, 1970-1995. Organização. Reges Sodré (2014).

Na série histórica da Tabela 1, as cidades médias de Araguaína e Gurupi apresentam crescimento médio anual superior ao das demais cidades, uma vez que estas crescem a uma taxa anual de 3,54\%, enquanto aquelas apresentam um percentual de crescimento de 6,54\%. O crescimento acumulado também se manifesta imponente, com 1330,36\% nas cidades médias e 331,44\% nas demais cidades.

Levando em consideração os dados apenas a partir da criação de Palmas, temos a acentuação da tendência, de modo que as três cidades médias, em 2006, representavam no estado $44,32 \%$ dos estabelecimentos de comércio e serviços e, em 2012, subiu para 49,96\%. O que impressiona é seu crescimento comparado com as outras cidades no mesmo período, pois essas cresceram 47,42\%, contra $17,53 \%$ das demais cidades. Esse crescimento pode ser atribuído ao desempenho econômico de Palmas que cresceu 64,46\%, bem superior a Araguaína (38,74\%) e a Gurupi $(20,94 \%)$.

Todavia, não podemos atribuir às cidades médias per se os avanços econômicos apresentados. Estes, sem dúvida, são significativamente delas tributário, mas há que se considerar que o estado do Tocantins, como um todo, tem sido alvo de expansão econômica em virtude da recente constituição de 
seu território, o qual oferece lacunas em que o capital pode encontrar grandes possibilidades acumulativas.

Assim, entre as 50 maiores empresas do Brasil em 2013, cuja atuação se dá em escala nacional e internacional, 25 estão presentes em cidades do Tocantins. Apenas uma, a multinacional Bunge, não se localiza nas cidades médias. A empresa encontra-se localizada na cidade de Pedro Afonso devido à forte dinâmica do agronegócio ali presente. Além disso, no Quadro 1 aparecem 05 empresas, em destaque itálico, que além das cidades médias localizam-se em outras cidades do estado. São elas a Ford, a Odebrecht, a Tim, a Ambev e a Telefônica. Foi possível identificar também que 05 empresas atuam somente em Palmas (Grupo Pão de Açúcar, Tam, Atacadão, Renault e Gerdau Aços Longos), enquanto outras 02 apenas em Araguaína (Toyota e JBS). Por esses dados fica inteligível como os grandes negócios têm como escolhas locacionais preferidas no estado do Tocantins as cidades médias, engendrando com suas instalações o avanço da centralidade dessas cidades e elevando a concentração espacial delas no estado.

Quadro 1: As maiores empresas do país presentes nas cidades médias do Tocantins

\begin{tabular}{|l|l|r|l|l|}
\hline \multicolumn{1}{|c|}{ Empresas } & \multicolumn{1}{|c|}{ Setor } & Lucro & \multicolumn{1}{|c|}{ Sede no Brasil } & \multicolumn{1}{|c|}{ Origem } \\
\hline $\begin{array}{l}\text { Ipiranga } \\
\text { Produtos }\end{array}$ & Atacado & 426,7 & São Paulo-SP & Brasil \\
\hline Volkswagen & Autoindústria & NI & S. Bernardo do Campo-SP & Alemanha \\
\hline Fiat & Autoindústria & 172,6 & Betim-MG & Itália \\
\hline Telefônica & Telecomunicação & $1.311,80$ & São Paulo-SP & Espanha \\
\hline Via Varejo & Varejo & 458 & S. Caetano do Sul-SP & Brasil \\
\hline Tim & Telecomunicação & 705 & Rio de Janeiro-RJ & Itália \\
\hline Correios & Serviços & 95,3 & Brasília-DF & Brasil \\
\hline Ambev & Bens de Consumo & $3.031,30$ & São Paulo-SP & Bélgica \\
\hline $\begin{array}{l}\text { General } \\
\text { Motors }\end{array}$ & Autoindústria & 0 & S. Caetano do Sul-SP & EUA \\
\hline Claro & Telecomunicação & $-510,9$ & São Paulo-SP & México \\
\hline Telemar & Telecomunicação & 171,5 & Rio de Janeiro-R & Brasil \\
\hline $\begin{array}{l}\text { Mercedes- } \\
\text { Bens }\end{array}$ & Autoindústria & 0 & S. Bernardo do Campo-SP & Alemanha \\
\hline Globo & Comunicações & $1.020,70$ & Rio de Janeiro-RJ & Brasil \\
\hline $\begin{array}{l}\text { Ale } \\
\text { Combustíveis }\end{array}$ & Atacado & 28,9 & Natal-RN & Brasil \\
\hline Ford & Autoindústria & 0 & S. Bernardo do Campo-SP & EUA \\
\hline $\begin{array}{l}\text { MAN Latin } \\
\text { America }\end{array}$ & Autoindústria & 0 & São Paulo-SP & Alemanha \\
\hline Odebrecht & Indústrias diversas & 607,3 & Rio de Janeiro-RJ & Brasil \\
\hline
\end{tabular}




\begin{tabular}{|l|l|r|l|l|}
\hline $\begin{array}{l}\text { Grupo Pão } \\
\text { de Açúcar }\end{array}$ & Varejo & 424,4 & São Paulo-SP & França \\
\hline JBS & Bens de Consumo & 363,6 & São Paulo-SP & Brasil \\
\hline Tam & Transporte & 0,5 & São Paulo-SP & Brasil \\
\hline Toyota & Autoindústria & 0 & S. Bernardo do Campo-SP & Japão \\
\hline Atacadão & Varejo & 0 & São Paulo-SP & França \\
\hline Renault & Autoindústria & 95,6 & São Paulo-SP & França \\
\hline $\begin{array}{l}\text { Gerdau Aços } \\
\text { Longos }\end{array}$ & $\begin{array}{l}\text { Siderurgia e meta- } \\
\text { lurgia }\end{array}$ & 385,4 & Rio de Janeiro-RJ & Brasil \\
\hline Gol & Transporte & $-244,8$ & São Paulo-SP & Brasil \\
\hline Bunge & Bens de Consumo & 73,6 & Gaspar-SC & Holanda \\
\hline
\end{tabular}

Fonte: Revista Exame (2013); Sites das empresas.

Por outro lado, a instalação dessas empresas nas cidades médias tem por base a área de atuação delas na rede urbana. Desse modo, tais empresas levam em consideração para instalação nessas cidades, não somente seu potencial interno de consumo, mas a distância que os consumidores de cidades vizinhas, ou não, estejam dispostos a se deslocar para realizar suas compras. Não à toa, os dados comprovam que a cidade de Palmas, com maior centralidade, possui também mais empresas de grande porte apenas nela localizadas.

Além disso, é importante destacar que as cidades médias logram de modernização de seus setores logísticos, em termos modais, e da proximidade com regiões agrícolas dinâmicas, na medida em que esses fatores, para alguns tipos de empresas (do agronegócio, petrolíferas, atacadistas), são determinantes em suas escolhas locacionais.

Ainda que alguns grupos econômicos escolham manter sua logística em pátios multimodais fora das cidades médias, é nelas sobremaneira que situam os escritórios e os representantes. Exemplo disso é o grupo JC Distribuição, o qual está entre os 10 maiores atacadistas do Brasil, segundo a Revista Exame (2013). Tal grupo atua no Tocantins com representantes nas cidades de Palmas, Gurupi, e Araguaína, ainda que nestas últimas adotem como ponto logístico os pátios multimodais de Colinas do Tocantins e Porto Franco.

O Makro Atacadista, do grupo holandês SHV Holdings, que figurou como o maior do Brasil nesta fatia de mercado em 2013, segundo a Revista Exame, está localizado na cidade de Palmas.

Quando se refere aos varejistas, perceber-se que os 50 maiores grupos do Brasil em 2012, segundo o Ranking IBEVAR (2013), não estão pulverizados em todo o espaço nacional, havendo ainda relativa concentração no centro-sul. Mas, quando da sua presença no Tocantins, as localizações preferidas são as cidades 
médias, principalmente Palmas, promovendo forte concentração de serviços especializados e mais diversificados nessa cidade. Dos 16 mais importantes grupos varejistas do Brasil em 2013, localizados nesse estado, 56,25\% estavam apenas em Palmas (Lojas Renner S.A., Lojas Riachuelo, Lojas Marisa, McDonald's, Grupo Mateus, Havan, Grupo SBF, Grupo Pão de Açúcar e Grupo Carrefour). Os outros grupos localizavam-se, principalmente, em Araguaína, Gurupi e, secundariamente, em cidades como Porto Nacional, Paraíso do Tocantins e Colinas do Tocantins.

A chegada desses novos capitais promove nos espaços locais a fragmentação e o fechamento de unidades comerciais, de serviços e industriais. Estes não logram da mesma variedade de produtos oferecidos e de acesso ao marketing junto à mídia e de financiamento junto ao estado. A esfera pública, aliás, tem se mostrado uma grande incentivadora da vinda de grandes empresas para o Tocantins. Convive também com esse quadro a competição que essas corporações estabelecem com grupos locais consolidados. Tais grupos, por sua vez, procuram alargar sua acumulação expandindo-se com novas unidades nas cidades de origem e para outros centros locais e pequenas cidades, mantendo a sua já "conquistada clientela". A título de exemplo tem-se o grupo Nosso Lar, de Araguaína, e do Quartetto Supermercados, em Palmas, que, apesar da pressão sofrida pela chegada das Casas Bahia e da presença de grupos como o Pão de Açúcar e Carrefour, mantém sua expansão.

Outra decorrência da chegada desses grupos multinacionais e nacionais e a competição ocasionada com os locais/regionais é a gestação, diversificação e expansão direta (e certamente indireta) de serviços complementares a suas funções. Entre eles estão terceirizações, serviços de manutenção em equipamentos eletrônicos, serviços gerais, segurança, alimentação e serviços especializados em contabilidade, advocacia, publicidade, entre outros.

Outro dado que corrobora com a perspectiva que estamos desenvolvendo refere-se ao potencial de consumo dos municípios brasileiros, apresentados pela empresa IPC Marketing Editora. Os dados mostram que as cidades médias do Tocantins no período de 1997 a 2013 tiveram um crescimento na participação do consumo no Tocantins de 14,55\%. Em 1997 as três cidades médias representavam 33,30\% do consumo estadual e, em 2013 subiu para 47,85\%.

Com isso, não é estranho que os serviços financeiros e o movimento de crédito e dinheiro tenham notável força nessas cidades médias tocantinenses. As três cidades médias concentram 40,15\% das agências bancárias do estado, com destaque para Palmas com 32 agências, enquanto Araguaína e Gurupi têm 12 e 8 respectivamente. Em 2014, 63,56\%, cerca de 141.639.679.61 milhões de 
reais, do total de operações em crédito no estado concentrava-se nas cidades médias. Palmas sozinha tinha 40,89\% das operações, enquanto relacionada com Araguaína detinham 54,75\% das operações de crédito. Destacam-se os bancos Rabobank Brasil S.A, Banco Triangulo S.A, Banco BMG S.A, Banco Santander S.A., que estão presentes apenas em Palmas. As outras instituições presentes nas três cidades médias são: Banco do Brasil, Caixa Econômica Federal, Itaú Unibanco BM S.A., HSBC Bank Brasil S.A e Banco da Amazônia S.A. (BRASIL, 2013).

Isso mostra não somente quão concentrados estão os serviços financeiros no estado do Tocantins, mas evidencia as precárias condições infraestruturais das cidades locais e pequenas. Estas, quando possuem agências bancárias, são alvos fáceis de quadrilhas especializadas em roubos de bancos. Por outro lado, nas cidades pequenas estão presentes vários caixas eletrônicos e atendimento conjugado com os Correios, que atendem à demanda da população de baixa renda, como aqueles beneficiários de programas sociais. Outra parte da população que necessita de suporte financeiro mais complexo, como comerciantes e agropecuaristas, acabam sendo "forçados" a se deslocar até as cidades médias.

No tocante à informação e comunicação, por meio de filiais de emissoras de TV, a disparidade é congruente. A TV Globo atua no Tocantins por meio da filiada TV Anhanguera, em Araguaína, Gurupi e Palmas, com 48, 17 e 22 municípios cobertos respectivamente. Gurupi tem 185.904, Palmas 455.769 e Araguaína 537.743 consumidores potenciais. A TV Bandeirantes tem afiliadas em Palmas, Araguaína e Gurupi, enquanto a Rede Record localiza-se apenas em Palmas, ainda que o sinal seja para quase todo o Estado (ATLAS DA COBERTURA DE TV NO BRASIL, ano?) ${ }^{4}$.

Ainda referindo-se aos meios de comunicação e informação, a pesquisa Mapa da Inclusão Digital 2012, elaborado pela Fundação Getúlio Vargas e pelo Centro de Políticas Sociais, mostra que o Tocantins figura nas últimas posições do ranking nacional em termos de microcomputador por domicílio (22 ${ }^{\underline{a}}$ posição) e com acesso à internet (23a $)$. Não obstante, os maiores índices são verificados nas cidades médias, sendo que mais uma vez Palmas é destaque, com média de 47,11\% de computadores por domicílios, em que 37,34\% tem acesso à internet. Em seguida aparece Gurupi com 38,17\% e Araguaína 33,59\% microcomputador por domicílio, e 28,75\% e 25,15\%, respectivamente, em relação ao uso de internet.

Quando associados esses números com o mercado de trabalho, têmse a ratificação dos resultados, visto no alto grau de concentração espacial

4 Utilizamos apenas essas três emissoras pela disponibilidade de dados, não se considerando, portanto, todas as emissoras presentes no estado. 
das atividades econômicas nas cidades médias do estado do Tocantins. Em decorrência desses processos, o dinamismo da geração de empregos formais no estado está atrelado, guardadas as ressalvas anteriores, ao próprio crescimento das cidades médias, acentuado nos últimos 25 anos.

Conforme os números da Tabela 2, em 1990 havia 28,181 mil empregos formais ${ }^{5}$ no estado do Tocantins. Esse número subiu para 37,167 mil, em 2000, e atingiu 257,536 mil, em 2013, consolidando um crescimento absoluto no período de $813,86 \%$.

Tabela 2: Numero de empregos formais nas cidades médias do Tocantins

\begin{tabular}{l|c|c|c}
\hline \multicolumn{1}{c|}{ Cidades } & 1990 & 2000 & 2013 \\
\hline Araguaína & 5,727 & 10,152 & 31,085 \\
\hline Gurupi & 4,089 & 6,907 & 14,787 \\
\hline Palmas & $\mathrm{x}$ & 51,817 & 115,888 \\
\hline Outras cidades & 18,365 & 37,167 & 95,776 \\
\hline Total & 28,181 & 106,043 & 257,536 \\
\hline
\end{tabular}

Fonte: Ministério do Trabalho e Emprego, 1990; 2000; 2013.

Nesse cenário, Araguaína e Gurupi, em 1990, concentravam 34,83\% do total de empregos formais estaduais. Em 2000, com a inserção de Palmas na contabilidade do TEM, tem-se o aumento da participação das cidades médias em 64,95\%. Já em 2013, houve uma pequena queda na participação percentual, redução em $62,81 \%$. Isso ocorreu porque o crescimento dos empregos formais nas outras cidades foi $22,83 \%$ superior ao das cidades médias. Esse dinamismo ocorre em parte devido à expansão de atividades do agronegócio em cidades locais. Ainda assim, as cidades médias possuem grandes vantagens sobre as demais e não invalida nossa hipótese inicial, pelo contrário, a ratifica.

\section{CONSIDERAÇÕES FINAIS}

É no encontro do movimento entre as relações de centralidade das cidades médias com as regiões de influência, relações gestadas historicamente, iniciada no contexto de expansão da fronteira dos anos de 1960 em diante e fortalecido com a criação do Tocantins em 1988, que elas são convocadas a desempenhar variados papéis no suprimento de bens e serviços para os centros locais e cidades pequenas. Estes, por sua vez, tornam-se mais exigentes quanto

5 No entanto, esse aumento não tem satisfeito o empresariado do Tocantins. Conforme o Jornal DAQUI, (2014, p. 5) "entre as reclamações apontadas pelos empresários estão falta de profissionais qualificados em áreas especificas, a deficiência na formação básica, além da falta de interesse do profissional em procurar qualificação". 
à oferta, principalmente, naqueles centros onde há maior avanço da fronteira agrícola de grãos.

A interiorização do capital nacional/multinacional influenciado pela reestruturação geral do capitalismo e pelas ações do Estado brasileiro, de um lado, impondo às cidades médias avançados níveis qualitativos na oferta de bens e serviços e, de outro, o aumento expresso no número de estabelecimentos comerciais e de serviços criados por agentes locais e regionais nessas cidades, colocam-nas sob crescentes índices de concentração espacial e econômica.

Tais índices referem-se ao quantitativo dos estabelecimentos comerciais, de serviços, industriais, geração de empregos, consumo e na amplitude dos capitais instalados, ou seja, das grandes empresas de atuação no território nacional que oferecem serviços mais especializados e diversificados, pondo em relevo a dimensão qualitativa. Pudemos constatar que com a ausência de metrópoles no Tocantins, são as cidades médias que assumem o protagonismo socioeconômico, atraindo os principais investimentos e comandando a rede urbana, de um lado, polarizando um conjunto amplo de centros locais e pequenas cidades, pela oferta de bens e serviços especializados e diversificados, de outro, estabelecendo amplas interações espaciais com o espaço nacional e internacional.

Não se pode negligenciar que Araguaína, Palmas e Gurupi possuem diferenças em seus espaços intraurbanos e quanto à abrangência das regiões de influência, dando especificidade a diferenciação dos processos de concentração econômica nessas cidades. Palmas claramente se destaca no cenário regional entre as três cidades médias, dentre outras coisas, por concentrar funções e atividades administrativas. A capital do estado tocantinense também possui as credenciais para ser uma cidade média, em termos de funções urbanas não apresentado quesitos de centro metropolitano e muito menos de cidade pequena. Araguaína aparece como a segunda mais importante cidade média, com uma rede de influência extensa no norte do Tocantins, sudeste do Pará e oeste do Maranhão. Essa cidade padece, todavia, de fraca infraestrutura urbana e da atuação de uma elite ainda pouco empreendedora. Gurupi, apesar de ter uma restrita área de influência, em parte devido à proximidade com Palmas, possui consolidado papel no sudoeste do Tocantins no âmbito do comércio, serviços e agroindústrias. Ademais, Araguaína e Gurupi apresentam fortes papéis relacionados ao agronegócio globalizado. 


\section{REFERÊNCIAS}

AJARA, C. al et. O estado do Tocantins: reinterpretação de um espaço de fronteira. Revista Brasileira de Geografia, Rio de Janeiro. v. 53, n. 4, p. 5-48, out/dez. 1991. Disponível em: <http://www.ibge.gov.br> Acesso em: 02 abr. 2013.

AMORIM FILHO, O.; SERRA, V. S. Evolução e perspectivas do papel das cidades médias no planejamento urbano e regional. In: ANDRADE, Thompson A.; SERRA, R. V. (Org.). Cidade médias brasileiras, Rio de Janeiro: IPEA, 2001. p. 1-34.

ANDRADE, T. A.; SERRA, R.V. As cidades médias e o processo de desconcentração espacial das atividades econômicas no Brasil: 1990/95. NEMESIS. Rio de Janeiro, 1998. Não publicado

BAUMAN, Z. Vida para consumo: a transformação das pessoas em mercadorias. Rio de Janeiro: Zahar, 2008.

BECKER, B. K. Política regional e mobilidade populacional numa fronteira de recursos do Brasil. Revista Brasileira de Geografia, Rio de Janeiro, v. 47 (3/4), p. 146-168, jul/dez. 1985. Disponível em: <http://www.ibge.gov.br> Acesso em: 02 abr. 2013.

Fronteira e urbanização repensadas. Revista Brasileira de Geografia. Rio de Janeiro, v. 41 (4), p. 357-371, out/dez. 1979. Disponível em: <http://www.ibge. gov.br> Acesso em: 02 abr. 2013.

BESSA, K.; CORADO, V. R.. A dinâmica recente do segmento de rede urbana no Tocantins: as implicações da construção de Palmas para Porto Nacional. GeoTextos, Salvador, v. 7. n. 1, p. 31-57, 2011. Disponível em: <https://portalseer.ufba.br/ index.php/geotextos> Acesso em: 20 jul. 2013.

BRASIL. Banco Central. Estatística Bancária por município. Disponível em: <http://www.bcb.gov.br/pt-br/paginas/default.aspx> Acesso em: 02 abr. 2013.

BRITO, E. P. de. O papel de Palmas-TO na rede de integração regional. 2009. 262 f. Dissertação (Mestrado em Geografia) - Universidade Federal da Grande Dourados, Dourados-MS, 2009.

CORRÊA, R. L.. Reflexões sobre a dinâmica recente da rede urbana brasileira. In: ENCONTRO NACIONAL DA ANPUR, 9. Rio de Janeiro, 2001, Anais... Rio de Janeiro, v, 2, 2001. p. 424-430.

DINIZ, C. C.; CROCCO, M. A. Reestruturação Econômica e Impacto Regional: um novo mapa da indústria brasileira. Nova Economia, Belo Horizonte, v. 6, n. 1, p. 77-103, 1996. 
EXAME - melhores e maiores. Maiores empresas do Brasil em 2013. São Paulo: Abril, 2013a.

As 10 maiores redes atacadistas do Brasil, segundo a Abad. São Paulo: Abril, 2013b.

FORNARO, A. C. Logística e agronegócio globalizado no estado do Tocantins: um estudo sobre a expansão das fronteiras agrícolas modernas no território brasileiro. 2012. 175f. Dissertação (Mestrado em Geografia) - Instituto de Geociências, Universidade Estadual de Campinas, Campinas-SP, 2012.

FRESCA, T. Centros locais e pequenas cidades: diferenças necessárias. Revista Mercator, Fortaleza, n. especial, p. 75-81, dez. 2010. Disponível em: < http://www. mercator.ufc.br/index.php/mercator>. Acesso em: 19 abr. 2015.

HARVEY, D. Condição pós-moderna. São Paulo: Loyola, 1998.

HARVEY, D. Alternativas ao neoliberalismo e o direito à cidade. Revista Novos Cadernos NAEA, v. 12,n. 2, agost-dez 2019, pp. 269-274

IBEVAR - Instituto Brasileiro de Executivos de Varejo e Mercado de Consumo. Ranking IBEVAR, 120 Maiores empresas do varejo brasileiro. São Paulo, 2013.

IBGE. A legislação municipal, municípios vigentes-2012. Disponível em: <www.ibge.gov.br>. Acesso em: 05 fev. 2014.

Censo Demográfico-1970, 1980, 1991, 2010. Disponível em: <www.ibge. gov.br>. Acesso em: 22 set. 2012.

Regiões de influência das cidades-2007. Rio de Janeiro, 2008.

Regiões de influência das cidades-1978. Rio de Janeiro, 1987.

Regiões de influência das cidades. Rio de Janeiro, 1978.

Divisão do Brasil em regiões funcionais urbanas. Rio de Janeiro, 1972

IPEADATA. Número total de Estabelecimentos ou Unidades Locais Comércio, Serviços, 1970-1995. Disponível em: <http://www.ipeadata.gov.br/>. Acesso em: 02 set. 2014.

Número total de Estabelecimentos ou Unidades Locais Indústria, 1970-1995. Disponível em: <http://www.ipeadata.gov.br/>. Acesso em: 02 set. 2014.

MACHADO, L. A fronteira agrícola na Amazônia brasileira. Revista Brasileira de Geografia. Rio de Janeiro. v. 54 (2), p. 27-56, abr/jun. 1992. Disponível em: < http:// www.ibge.gov.br> Acesso em: 02 abr. 2013. 
MTE - Ministério do Trabalho E Emprego. Relação Anual de Informações Sociais-1990, 2000, 2013. Disponível em: <http://portal.mte.gov.br/portal-mte/>. Acesso em: 05 fev. 2014.

SANTOS, M.; SILVEIRA, M. L. O Brasil: sociedade e território no início do século XXI. Rio de Janeiro: Record, 2008.

A natureza do espaço: técnica e tempo, razão e emoção. São Paulo: Edusp, 2012.

A urbanização brasileira. São Paulo: Edusp, 2009.

SODRÉ, R. As atividades do agronegócio em Araguaína: entre espacialidades urbanas e novas/velhas desigualdades sociais. 2014. 79f. Trabalho de Conclusão de Curso (Graduação em Geografia) - Universidade Federal do Tocantins, Palmas, 2014.

SPOSITO, M. E. B. Novas redes urbanas: cidades médias e pequenas no processo de globalização. Revista Geografia, Rio Claro-SP, v. 35, n. 1, p. 51-62, 2010. Disponível em: $\quad<$ http://www.periodicos.rc.biblioteca.unesp.br/index.php/ageteo/index > . Acesso em: 15 mar. 2014.

Globalização, consumo e papéis intermediários de cidades médias no Brasil. In: SANFELIU, Carmen Bellet; SPOSITO, Maria Encarnação Beltrão (Org.). Las ciudades medias o intermédias en un mundo globalizado. Lleida: Universitat de Lleida, 2009. p. $41-69$.

O chão em pedaços: urbanização, economia e cidades. 2004. 512f. Tese (Livre Docência em Geografia) - Faculdade de Ciências e Tecnologia, Universidade Estadual Paulista, Presidente Prudente-SP, 2004.

SPOSITO, M. E. B.; SPOSITO, E. S. Reestruturação econômica, reestruturação urbana e cidades médias. In: Seminário da Rede Iberoamericana de Pesquisadores sobre Globalização e Território (RII), 12. Belo Horizonte, 2012. Anais... Belo Horizonte, 2012, v. 1. p. 1-17.

SPOSITO, E. S.; SANTOS, B. S. O capitalismo industrial e as multinacionais brasileiras. São Paulo: Outras Expressões, 2012.

TRINDADE JR., S.-C. C. da. Cidades médias na Amazônia oriental: das novas centralidades à fragmentação do território. Revista Brasileira de Estudos Urbanos e Regionais, v. 13, n. 2, p. 135-151, nov. 2011. Disponível em: < http:/ / rbeur.anpur. org.br/rbeur/article/viewFile/399/375>. Acesso em: 19 abr. 2015. 